\title{
Better Science Through Art
}

\author{
$\left.\begin{array}{c}\text { Richard P. Gabriel } \\ \text { IBM Research } \\ \text { Hawthorne, New York USA }\end{array}\right\}$ rpg \\ rpg@\{ $\begin{aligned} & \text { us.ibm.com } \\ & \text { dreamsongs.com }\end{aligned}$
}

\begin{abstract}
How do artists and scientists work? The same.

Categories and Subject Descriptors A.0 [General]

\section{General Terms Design}

Keywords Design, art, science, software engineering

$$
u^{n}
$$ \\ Prefrontal lightningbolt too lazy to chew the sphinx's loudest eyelash \\ Not even if it shushes you with a mast of sneers \\ Down which grateful bankvault-doors scamper \\ Because of a doublejointedness that glows in the dark \\ Like a soliloquy of walnuts \\ Numbed by beaks of headless measuringtape \\ So the lubriciousness can tower in peace \\ Like a buzzsaw trapped in a perfumery of shrugs \\ Lemon \\ Or lime \\ Only a maze can remember your hair of buttered blowguns \\ From Nights of Naomi by Bill Knott [1]
}

Art is strange. Art cannot be understood. The poet Robert Browning is reported to have said of a passage he wrote:

When I wrote that, God and I knew what it meant, but now God alone knows.

Science and art don't seem directly related. Except people do science. And people do art. Science is a clear statement of truth in the actual world. Behold the simplicity of science:

$$
\begin{gathered}
A_{N}=\int D \mu \int D[X] \exp \left(-\frac{1}{4 \pi \alpha} \int \partial_{z} X_{\mu}(z, \bar{z}) \partial_{\bar{z}} X^{\mu}(z, \bar{z}) d z^{2}+i \sum_{i=1}^{N} k_{i \mu} X^{\mu}\left(z_{i}, \bar{z}_{i}\right)\right) \\
A_{4}=\frac{\Gamma\left(-1+\frac{1}{2}\left(k_{1}+k_{2}\right)^{2}\right) \Gamma\left(-1+\frac{1}{2}\left(k_{2}+k_{3}\right)^{2}\right)}{\Gamma\left(-2+\frac{1}{2}\left(\left(k_{1}+k_{2}\right)^{2}+\left(k_{2}+k_{3}\right)^{2}\right)\right)}
\end{gathered}
$$

This work is licensed under the Creative Commons Attribution-Noncommercial-Share Alike 3.0 United States License. To view a copy of this license, visit http://creativecommons.org/licenses/by-nc-sa/3.0/us/

or send a letter to

Creative Commons

171 Second Street, Suite 300

San Francisco, California, 94105, USA.

\author{
kjs \{ \\ Kevin J. Sullivan \\ University of Virginia \\ Charlottesville, Virginia USA \\ sullivan.kevinj@gmail.com
}

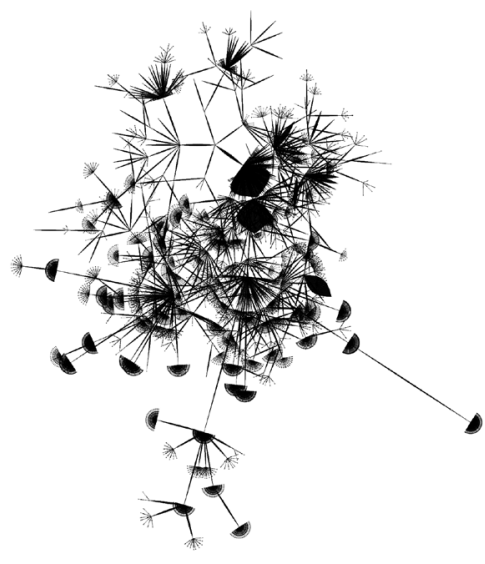

This is a sort of contemporary science which is more easily understood than the nonsensical poem.

Don't you think? Ah, but with training this is quite easily understood. The poem, however-obviously no amount of training, teaching, or learning will bring you to understand it.

Some other examples: a visual representation of a source code svn log shows, clearly, the history of the program, whereas the Jackson Pollock painting is clearly less understandable

Some mathematicians have computed the fractal dimension of some of Pollock's drip paintings as high as 1.72thickly layered and complex.

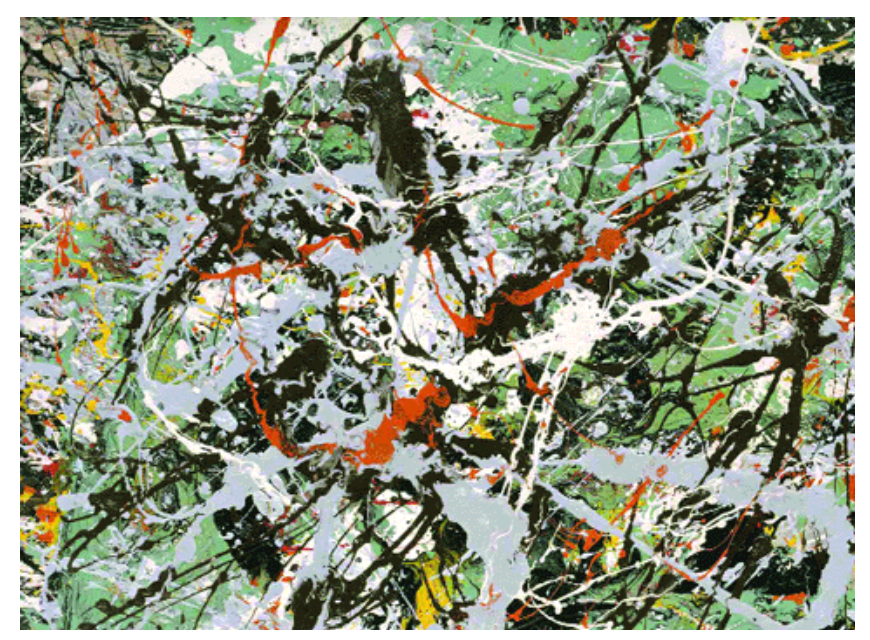




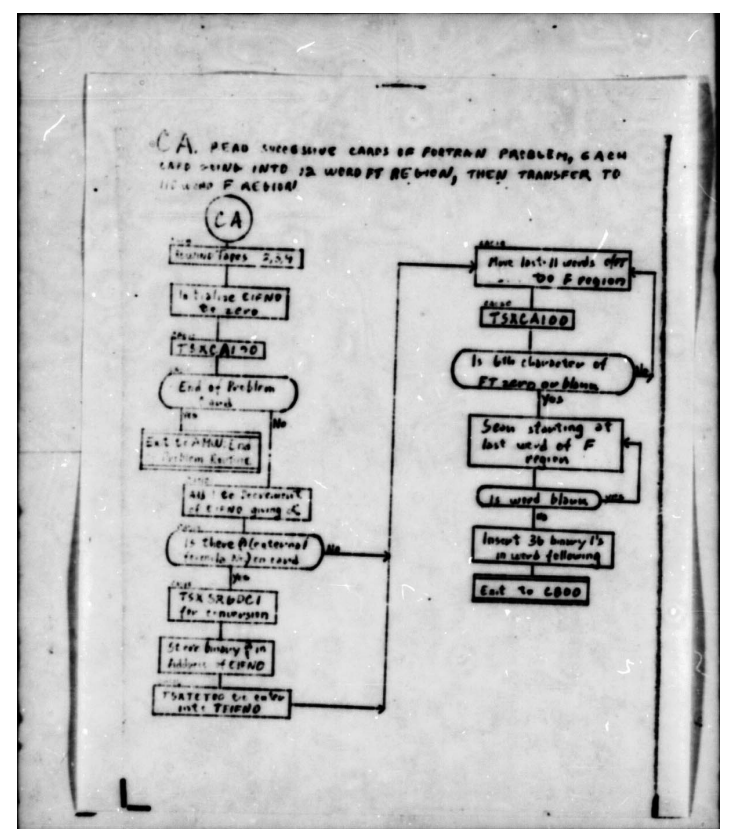

Other representations of source code are more prosaic, and tell the story of a human mind at work using human hands-and sometimes we wonder whether writing code out by hand would help a programmer better understand what he or she is doing. Some human designs seem a bit sloppy, or even pieced together, but still we can see the human mind at work even through the mess and erasures.

The work below by Sanda Illescu is based on a recursive writing / erasing / rewriting process in which a poem by Wallace Stevens is written, erased, and then the same poem with one fewer line is written again; the process halts when only one line-the first line-remains. A surrounding recursion produces a total of 24 pieces like this where the first is the most heavily written and erased and the last is the least. This is the $13^{\text {th }}$ in the sequence.

kjs, working with Sanda, captured the formal structure of her process as a Java program. Around this formal structure, however, Sanda engaged in a non-deterministic, human process of noticing and responding to the situation in ways that are human and resistant to easy expression in algorithmic

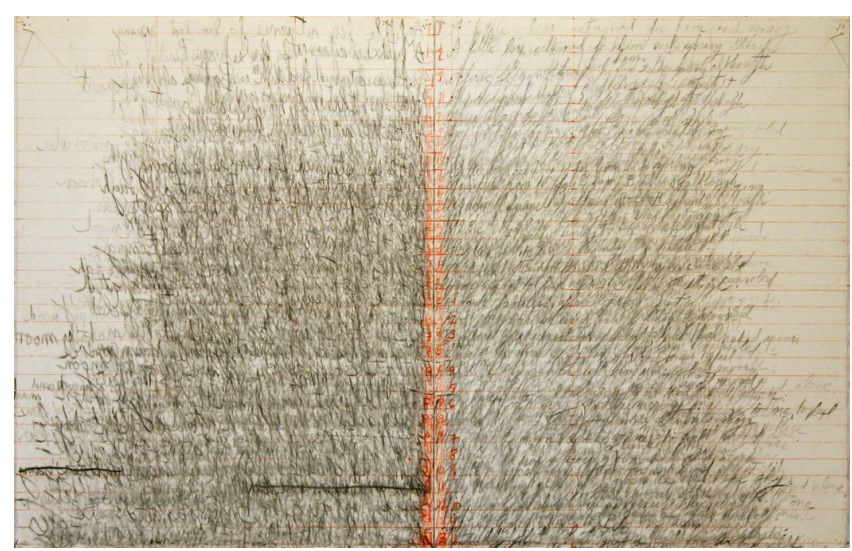

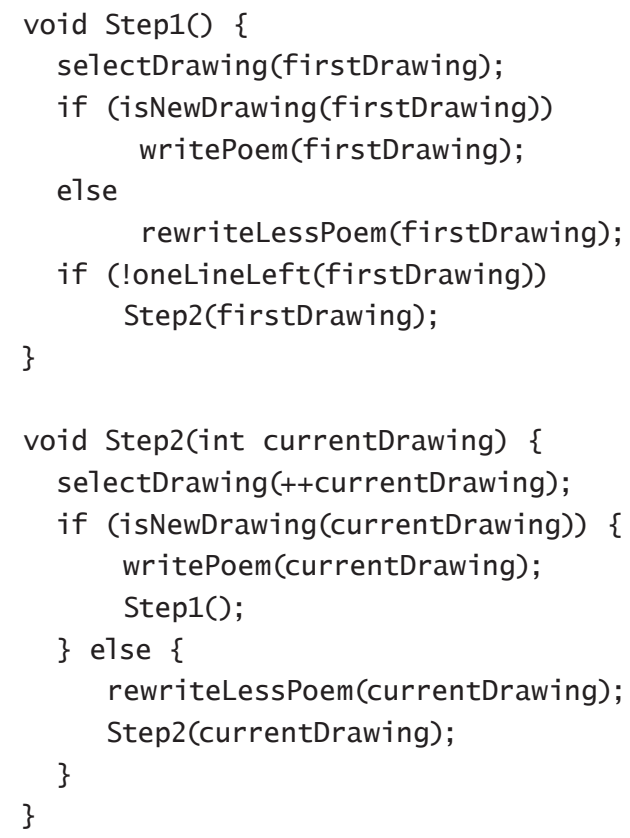

form-finding a new interpretation of the poem through repeated reading and writing; seeing and then responding to imperfections in the paper.

Art is, in part, the practice of intense and disciplined noticing-of details, of life, of how the world works-and in that way at least it resembles science.

Many artists use processes or formal techniques to increase the opportunities for noticing-artists don't simply visit their cafés every day, do their laundry, and put their (very interesting) cats in their art. Some of those techniques include types of sampling, stochastic or otherwise.

For many, science appears in caricature-science is a process and a way of thinking; individuals practice that process and way of thinking to perfection, the result being a steady progression of increased and perfected knowledge over the millennia-the forward march of science. In this caricature, scientists

- ereate knowledge

- study the world as it is

- are trained in the scientific method

- use explicit knowledge

- are thinkers

In fact, this is not the case. Not only is it not clear what science really is and how it's practiced, but in terms of purely being right, science is one of the most failure-prone of disciplines, with theories being overturned and subsumed all the time. Aristotelian science overturned by Newton subsumed 


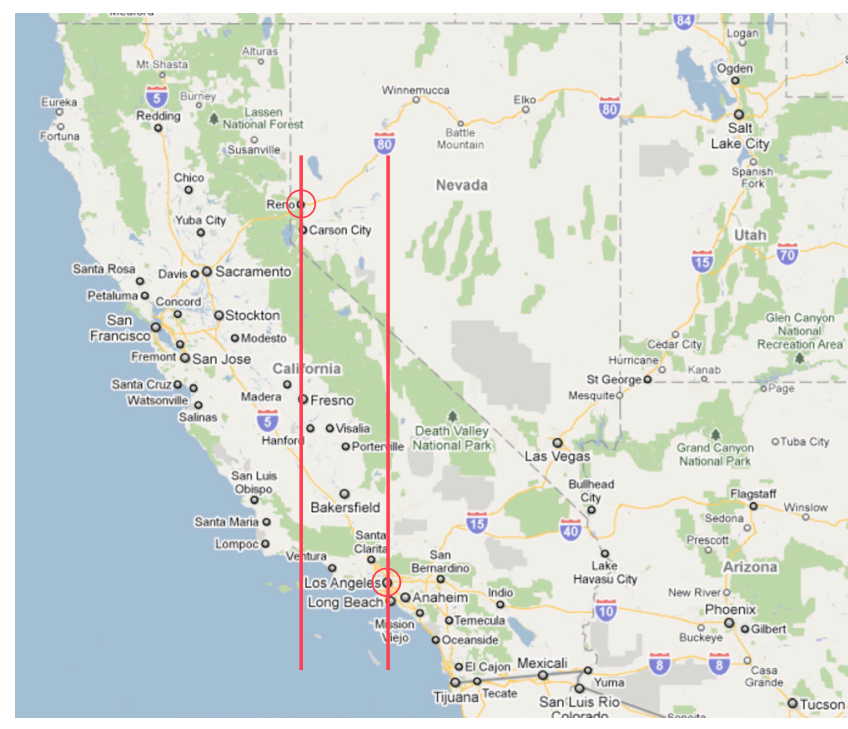

by Einstein, Ptolemy overturned by Copernicus, Lamarck ${ }^{1}$ by Darwin. And on and on.

Along with that caricature is a companion for engineering. Engineering, it's thought, is only the application of science, and with that is a belief-perhaps not deeply held but at least a first approximation-that science always precedes engineering, and that without science there could be no engineering.

Important in thinking about art, science, and engineering are the ideas of explicit and tacit knowledge.

Explicit knowledge is something that can be written down and is thereby fully and accurately transmitted. Here is an example:

\section{Los Angeles is east of Reno.}

For some this is be new information, and perhaps it requires some verification, but once you have read, understood, and believed this sentence, you know it as well as anyone.

Tacit knowledge depends on practice and, to an extent, skill. Knowing how to design, for example, requires tacit knowledge.

Artists are thought to use an educated sense of aesthetics to work effectively. Artists typically have a highly trained skill or talent, such as the ability to draw, paint, sculpt, write, or compose music. In this caricature, artists

- ereate artifacts

- study the world as it appears

- are trained in acreational skill

- tse aesthetics and tacit knowledge

- aredoers or expressers
When viewed according to these caricatures, art, engineering, and science appear to be very different disciplines requiring different abilities, skills, likes, desires, and motives.

Science is a complicated beast. People who study how science works cannot agree on what they see. What follows is a quick tour of the landscape, each the view of a respected philosopher of science.

Demarcation problem: the study of what science is focuses on the question of what separates scientific ideas, statements, and theories from pseudoscience-or voodoo, if you will. This is called the demarcation problem.

Further, the demarcation problem includes finding out how "science" determines whether one theory is "better" than another, thereby invoking a scientific revolution in the Kuhnian sense [7].

Positivism has been the dominant "theory" of science for many centuries, and particularly so in the $20^{\text {th }}$ and $21^{\text {st }}$ centuries. In fact, some consider it the current received theory. ${ }^{2}$ Positivism is "the view that serious scientific inquiry should not search for ultimate causes deriving from some outside source but must confine itself to the study of relations existing between facts which are directly accessible to observation" [8]. It rejects any appeal to metaphysics. Positivism states that we understand the world by looking at it-that reality is real, and that our sense perceptions are valid. This holds even when our perception is through mechanisms we create, such as scientific instruments.

Logical positivism adds the idea that rational or logical conclusions from observations and other scientific knowledge are also valid statements about the world.

Elitist authoritarianism: science proceeds by scientific publication. What counts as science is what's published in those conferences and journals that are labeled "scientific."

Such publication is based on the opinions of a jury of peers-peer review. Such juries are not elected or randomly selected but are chosen by program chairs and editors in chief, and so represent a kind of scientific in group, an inner circle.

Inductivism tackles the problem of how to establish universal statements given a finite and limited set of observations. It permits many similar observations to add up to a general statement about the universe. Inductivism is how we come to believe that a series of observations on or near Earth lead to valid scientific theories about the other side of the galaxy, other galaxies, and in fact, the other side of the universe.

Inductivism is based on two difficult requirements; first, that it is possible to bridge the gap from facts to factual propositions, and second, that it's possible to go from a finite set of observations to a universal law. It would be a statement of metaphysics to claim that our neighborhood of the universe

${ }^{2}$ Some form of positivism has been a recurrent theme since the early Greeks until today.

${ }^{1}$ Lamarck turns out not to be so overturned as we thought—c.f. epigenetics. 
is special, with laws that enable the existence of cognitive beings, for example. But to claim that our neighborhood is not special is science, according to inductivism.

These two requirements are impossible according to philosophers from previous centuries, and their reasoning is interesting wrt our exploration of what science is. The first requirement falters because a person is needed as the bridge between facts and propositions-to judge what is relevant and what isn't, and aesthetics can intervene.

The second requirement suffers an interesting critique as well. Aristotelian logic is about syllogisms, and for centuries it was considered the only valid form of logic, and especially of deduction. In the $17^{\text {th }}$ century-when science as we know it was born-scientists noticed that all the interesting logical derivations used some non-Aristotelian method of inference. Many of these derivations were relational, such as if $B$ and $\mathrm{C}$ are between $\mathrm{A}$ and $\mathrm{O}$, and $\mathrm{G}$ is between $\mathrm{B}$ and $\mathrm{C}$, then $\mathrm{G}$ is between $\mathrm{A}$ and $\mathrm{O}$. Because Aristotle and his ideas about logic were held in such high regard, this led scientists to conclude that the validity of a logical inference depended on the scientist's intuition, which meant logic was a psychological question. In fact, many scientists believed that an inference was valid exactly when a sane person felt it was valid. Moreover, with so many types of inference being possible, it turned out that there was reason to believe in content-increasing inferences, and hence inductivism was born, and as we'll see, content-increasing inferences are at the heart of doing science.

Probabilism is a brand of inductivism. Scientific statements are ones that can be shown to be probable, and one theory is better than another if it is more probable. Voodoo is not scientific because its probability is low-or because other theories are more probable.

The size of the universe and the small sample we have of it naturally mean that the probabilities behind our theories-if they would ever be actually computed-are small.

Conventionalism ducks the whole question of what's true in order to get at what's useful. In a sense, conventionalism takes engineering more seriously than it does truth, and posits that science is about coming up with mechanisms that make engineering calculations easy-and perhaps elegant. Conventionalism is one of the oldest takes on science. The very first "theory" was Ptolemy's system of spheres within spheres, which enabled him to predict very accurately the movement of planets and other heavenly bodies against earth's night sky. All this while maintaining that the earth was (or could be) at the center of the universe. Copernicus came along with a more accurate and simpler theory, but he failed to realize that he could protect himself against the anger of the Church by explaining that of course the views implied by his "theory" weren't true-contrary as they seemed to be to the Bible-but his theory was merely a way to simplify astronomical (and astrological) calculations.
Even in the $20^{\text {th }}$ century, many if not most physicists viewed quantum mechanics as a good predictive theory and not necessarily a statement about what is true in the universe.

Falsifiability is considered by many to the be primary characteristic of a scientific statement. If a statement can be falsified, it is scientific. Because an experiment can be an observation, there are many statements that are scientific that we might not think of that way.

$2+2=3$ is a scientific statement that happens to be false (by observation and elementary-school arithmetic).

This sentence no verb is similarly scientific, and true.

More importantly, there are two questions that make things problematic. The first is that if you need to construct an instrument as part of an experiment to verify a statement, and that instrument and understanding of what it measures depend on the theory being tested, then why should we believe that the instrument is capable of falsifying the theory? There needs to be a separate theory of how the instrument works and what it measures-but this can be a conventionalist theory in practice.

The other is that if a theory is well-established and an experiment falsifies the theory, how seriously should we take the refutation? In some cases the experimental data is thrown out. If it persists, usually the theory is patched to account for the discrepancy. And sometimes a deep analysis is undertaken to determine whether some variables are disturbing the results (the ceteris paribus or "all things being equal" situation).

Imre Lakatos tried to reconcile Popper's rational falsificationism with Thomas Kuhn's historical view of science in his take on research programmes.

Research Programmes: Lakatos claimed that science was performed in the form of a research programme in which a hard core of the theory was protected from direct patching by a cocoon of auxiliary hypotheses that could be modified to handle experimental discrepancies. Research programmes contain methodological statements that tell scientists what is good to work on and what isn't.

In this view, what many think of as a single theory is really a series of slightly different theories, where a later theory differs from its predecessor by being better or progressive. A theory is progressive (over the last) when it leads to new predictions, none of its bold (core) predictions have been falsified, and it is not patched by ad hoc statements, but instead retains its hard core and adjusts its protective belt. A series of theories like this is called a research programme, and when a research programme is no longer progressive, a new one emerges.

Popper required instances of nature saying NO be explained or the theory replaced; Kuhn observed "normal science" moving forward patching its theory until it was too unwieldy, and then replacing it during a sort of revolution.

Epistemological anarchism (anything goes): Paul Feyerabend-in some ways rpg's favorite philosopher of sci- 
ence-said that science really doesn't proceed in a rational manner, that there is no such thing as demarcation between science and voodoo, that there is no such thing as progress, and that one theory succeeds another only when the propaganda machine of the replacing theory's proponents overthrows the other's.

Actor Network Theory: Bruno Latour looks at science with a sociologist's eye [10]. He argues three ideas: science is what a jury decides it is; science is what gets done in a laboratory; accepted science is the result of a strong social network in which references accumulate to indicate what the overall community of scientists thinks about the work. In other words, to know what science is, visit Google Scholar.

These views teach us that science is not purely about the truth, scientists aren't (simply) objectively securing the truth from the clutches of nature, and science might after all simply be a convenient story about the world that enables us to build things.

And what of the idea that engineering depends on science? Here is how the American Engineers' Council for Professional Development defines engineering:

The creative application of scientific principles to design or develop structures, machines, apparatus, or manufacturing processes....

Let's look at engineering to start to connect art with science through engineering.

rpg: In 1995 I went back to school and got my MFA in Creative Writing - in poetry in fact. They tried to teach me how to notice things. In fact, the primary method of teaching fine arts is to show you how to observe and analyze closely so you can learn and improve on your own. If all you have for a teacher, for example, is a complicated poem written by a master, you must be able to see all the craft elements and thought processes the poet used to create that poem.

We think of engineers as craftsmen or sometimes even as laborers. But building things-as engineers do-requires people to manipulate materials and the physical world, and figuring out how to build things requires looking at the world very carefully. Therefore, engineers need tacit knowledge to do their work well. And tacit knowledge comes from practice and discipline, and being able to notice deeply-as artists do.

It shouldn't be surprising then to notice, when we look back on the history of science, that many or perhaps most of our scientific advances came from engineers, builders, and craftsmen working with materials, coming to understand them, and formalizing their characteristics.

What science contributes, mainly, is a way of thinking about materials and forces in ways that are computationally convenient and repeatable, in ways that reveal the properties and possibilities of nature. Science is a story with lessons that
Scientists

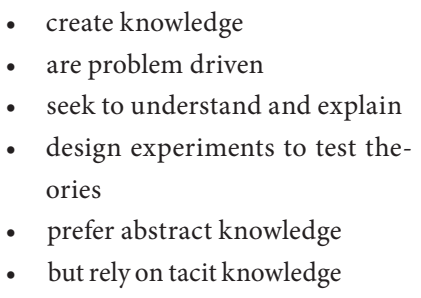

- create knowledge

- are problem driven

- seek to understand and explain

design experiments to test the

prefer abstract knowledge

- but rely on tacit knowledge
Engineers

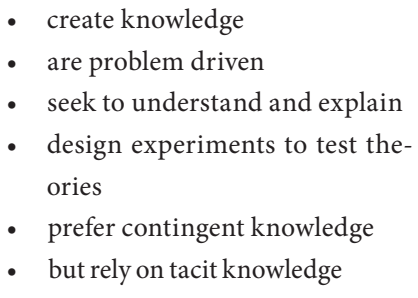

- create knowledge

- are problem driven

seek to understand and explain st theprefer contingent knowledge

but rely on tacit knowledge can be easily applied. These stories are in a computationally friendly language called mathematics.

Skilled manual labor entails a systematic encounter with the material world, precisely the kind of encounter that gives rise to natural science. From its earliest practice, craft knowledge has entailed knowledge of the "ways" of one's materials - that is, knowledge of their nature, acquired through disciplined perception....[I]n areas of well-developed craft practices, technological developments typically preceded and gave rise to advances in scientific understanding, not vice versa. [11]

One good example is the steam engine. It was developed while scientists were way into the caloric theory of heat. Looked at now, this theory is hilarious. It held that heat consisted of a fluid called caloric that flows from hotter to colder bodies. Caloric is a weightless gas that can pass in and out of pores in solids and liquids.

The amount of caloric in the universe is constant, so there is a sort of conservation that thermodynamics also recognizes.

A cup of hot coffee cools because caloric is self-repelling, so it disperses from the dense concentration in the cup to the less dense air.

When caloric enters the air, it combines with its molecules, and thus the air increases in volume. By expanding on what happens when caloric interacts with other matter we can explain heat radiation, phase changes (ice, water, steam, for example), as well as deduce most of the gas laws.

When Laplace corrected Newton's pulse equation with a constant to take caloric into account, the equation was better able to predict the speed of sound, and as this constant was refined under the caloric theory, even more precise predictions for the speed of sound were made for over a century.

The caloric theory was replaced, generally, by thermodynamics, but you know, the whole time steam engines continued to work, and they still do. ${ }^{3}$

Here is a more realistic view of scientists and engineers. Both scientists and engineers create knowledge through dis-

${ }^{3}$ Steam engines exploded during their early development and use, but this was due mostly to a lack of knowledge (scientific or engineering) about the strengths of materials. 
covery, are problem driven, and seek to understand and explain the world and things in it. Scientists design hypotheses and experiments, and engineers design devices-in fact, engineers help scientists design the devices used in their experiments. Scientists are more comfortable with abstract or universal ideas, and engineers with concrete or contingent knowledge. ${ }^{4}$ And both rely on tacit knowledge.

What's the essence of science? Discovery and verification. Verification is mostly what the philosophers of science concern themselves with, but without discovery, there is not so much to verify. Discovery is the heart scientific inquiry. Engineering, as we've seen, is one way discoveries happenfrom playing with materials, trying to bend them to our wills, using them to build with-and another way is simple noticing what's in front of you.

Langley, Simon, Bradshaw, and Zythow-Herb Simonnoticed similar things when writing about a system they wrote that engages in data-driven scientific discovery:

In the scientist's house are many mansions... .Outsiders often regard science as a sober enterprise, but we who are inside see it as the most romantic of all callings. Both views are right. The romance adheres to the processes of scientific discovery, the sobriety to the responsibility for verification.

...

Histories of science put the spotlight on discovery.... The story of scientific progress reaches its periodic climaxes at the moments of discovery....In the philosophy of science, all the emphasis is on verification, on how we can tell the true gold of scientific law from the fool's gold of untested fantasy. In fact, it is still the majority view among philosophers of science that only verification is a proper subject of inquiry, that nothing of philosophical interest can be said about the process of discovery.

But we believe that science is also poetry, and-perhaps even more heretical-that discovery has its reasons, as poetry does. However romantic and heroic we find the moment of discovery, we cannot believe either that the events leading up to that moment are entirely random and chaotic or that they require genius that can be understood only by congenial minds. We believe that finding order in the world must itself be a process impregnated with purpose and reason. [12]

Artists discover-they notice; it's what they're trained to do. It requires some talent to become an artist, but mainly it

${ }^{4}$ Contingent knowledge is knowledge that depends on the context or environment where one is working. takes practice and perseverance. Genius is rarely if ever part of the equation. ${ }^{5}$

But a step has been left out: exploration. Think of art. Discovery is the heart of any artistic endeavor. Discovering is noticing, and noticing naturally takes place on a journey, preferably a strange one. Artists often start out with no particular destination in mind when they start a project, and sometimes-this will be hard to believe at first-no starting point but simply what happens to occur to them at the start. Noticing is trained seeing, and not only what is there but what should be there.

And not just in art. Think of science. First exploration (Darwin on the Beagle), then discovery (Röntgen and X-rays), and finally understanding (Maxwell's equations).

Ordinary folks don't see as scientists or artists do. George Gamow et al. saw (predicted) that there should be a cosmic microwave background radiation (CMBR) left over from the big bang. Arno Penzias and Robert Wilson didn't ignore the low-level background signal from their radio telescope but worked hard to eliminate all possible explanations except CMBR. ${ }^{6}$ It turned out that what they were "seeing" was what had been "seen" (predicted) earlier. One does well to know what might be seen, and to know how to recognize it. Artists similarly know how to see. Painters and photographers see color differently from someone not trained as an artist.

Exploration is essential to artists-so essential that some artists use artificial mechanisms to ensure that the starting place and subject matter are substantially random and unplanned for in order to explore fruitfully. Artists have found it can be important to have a sort of defocused attention and to engage in flat associations-going broad not deep. This is exploration; by noticing we begin to discover. Discovery is making connections, and this is where metaphors pop up. Peter Turchi writes that exploration is "some combination of premeditated searching and undisciplined, perhaps only partly conscious, rambling," and that "if we persist, we discover" [13].

Exploration is opening the mind to possibilities; discovery can be literal discovery, such as finding a pot of gold at the end of a rainbow, but sometimes it's a guess-this is the best way to structure the story, the best image to convey the narrative or lyrical point, or the best explanation of what you saw while exploring; understanding is coming to believe (based on real evidence) that the discovery or guess is valid - that it is right, that it is what is needed, and perhaps why it's valid.

Turchi says, "exploration is assertive action in the face of uncertain assumptions, often involving false starts, missteps,

${ }^{5}$ C.f., e.g., The Talent Code by Daniel Coyle, The Genius in All of Us by David Shenk, and Multiple Authorship and the Myth of Solitary Genius by Jack Stillinger.

${ }^{6}$ Wikipedia reports on their scientific assiduousness: "After thoroughly checking their equipment, removing some pigeons nesting in the antenna, and cleaning out the accumulated droppings, the noise remained." 
and surprises" [13]. Discovery, as William Stafford might say, is a "reckless encounter with whatever comes along" [14].

Some writers start with a scene or a situation, sometimes just a sense or feeling - and that becomes a novel. The poet Bob Hass says he starts with a phrase, a word, or a line and a gesture, a physical gesture in the air which indicates, for example, a rising energy level or a decline or some more complicated shape-and the result is a poem [15].

Once a draft begins to take shape-a draft of a written piece or paint on the canvas or some shards off the rock or some notes on the guitar-a process of understanding begins. This is the revision process where what has been discovered is examined and the best story / painting / sculpture / composition is created. Sometimes these drafts are in the form of sketches or studies when the medium is not malleable.

Again, Turchi: "Only after discovery can the work be properly structured, can the selection and organization of the significant moments of time take place" [13]. He continues:

If we attempt to map the world of a story before we explore it, we are likely either to (a) prematurely limit our exploration, so as to reduce the amount of material we need to consider, or (b) explore at length but, recognizing the impossibility of taking note of everything, and having no sound basis for choosing what to include, arbitrarily omit entire realms of information. The opportunities are overwhelming. [13]

This is the full process of art-exploration, discovery, and then verification or understanding - and it's also the full process of science. Naturally, it's not a linear process but one with cycles of explore-discover-understand within any of its steps.

What's different between art and science is the emphasis given to the parts. Serious thinkers about the scientific process focus on verification and understanding. Making judgments about what's good science. What's nice about art is that there has been plenty of thought given to the early parts of the process: exploration and discovery-and we can learn from it.

Artistic creation is as much about being lost as exploring known-even half-known-territory. Great explorers don't explore the parts of the map that have names. Turchi sums it up like this:

Artistic creation is a voyage into the unknown. In our own eyes, we are off the map. The excitement of potential discovery is accompanied by anxiety, despair, caution, perhaps, perhaps boldness, and, always, the risk of failure. Failure can take the form of our becoming hopelessly lost, or pointlessly lost, or not finding what we came for (though that last is sometimes happily accompanied by the discovery of something we didn't anticipate, couldn't even imagine before we found it). We strike out for what we believe to be uncharted waters, only to find ourselves sailing
Artists

- create knowledge, language, alternative reality

- are image or "piece" driven

- seek to understand and explain

- design devices (their pieces) to explore the world and the self

- prefer contingent knowledge

- but rely on tacit knowledge

in someone else's bathtub. Those are the days it seems there is nothing new to discover but the limitations of our own experience and understanding. [13]

Art and science can be confused: at the beginning of recorded history there were a set of stories about how and why the world and people were created, why weather happens, why the earth moves under our feet, why the seasons change, why people are different, why their moods change, why there are families, how to plant, hunt, and live. Oceans, sky, fire, trees, animals. Matt Crawford writes:

Some of the oldest stories we know, including creation myths, were attempts to make sense of the world. Those early storytellers invented answers to the mysteries all around them. Why does the rain come? Why does it stop? If a child is created by two adults, from where did the first two adults originate? What is the earth like beyond what we have seen, and beyond what the people we know have seen? What lies beyond the stars? [11]

We call these stories literature now, or religious tracts. But at the time, they passed as science.

Looking at art objectively, given this more enlightened view, it seems that artists, engineers, and scientists are not so different after all.

They all create knowledge of one sort or another-sometimes "hard science" knowledge, sometimes "how to" knowledge, and sometimes "what about it" knowledge. Artists create language and other sorts of realities (like engineers). They work through the medium of the pieces of art they endeavor to create. Theses pieces are devices used to understand and explain the world. - And not just the natural world, but the world of human perception, conditions, values and ethics, emotions, etc. The subject matter and means of investigation are different, but the architecture of the processes are similar across the art, science, engineering spectrum. Should we coin a word for this process? Is it research?

And they all work with what's in front of them, using skills and talents that take time to acquire. 
Thus far we've muddied and complicated your ideas about science and art. We've deliberately made science look confusing, and in particular made it appear to be seeking knowledge without a solid philosophical footing. And we've made art look more principled than the simple yowling into the night many take it to be. That is, we've tried to explode your stereotypes.

And we've hinted that artists and scientists (and engineers) work in much the same way: each explores, each discovers, and each understands (verifies and/or validates).

But art-science is just one among perhaps many dimensions that might describe how people work on creative endeavors. Another is experimental-conceptual. This brings us back to noticing. How hard it is to notice when our rational minds try to layer our concepts on top of what is really out there. Our rational brains try to replace ongoing perception with symbols. Like a parser, we reduce the complex to the simple symbol, then move on; whereas art demands that we parse and parse again and parse again until we see what's there in a new way. - So that even the already-crazy artist sometimes needs to use artificial means to see things as they are.

Language-we're talking about language.

\section{$\sim^{n}$}

Over the last 2000 years there have been about 900 attempts to invent a language that is better than natural language-either to be more logical, to be more precise, to be easier to learn, or to eliminate perceived design flaws. One question about natural languages is that even though people quite obviously made them, how were they designed? Were they designed in any sense? Do they reflect a certain structure in our brains, our DNA, the background order of the universe?

Languages considered as engineering works are obviously flawed, and the good scientist or engineer desires to do better. Artists, though, seem to revel in natural language-love the mess the way painters love oils and watercolors, the unruliness of them all. Arika Okrent argues like this:

...the urge to invent languages is as old and persistent as language itself. It is at least as old and persistent as the urge to complain about language. The primary motivation for inventing a new language has been to improve upon natural language, to eliminate its design flaws, or rather the flaws it has developed for lack of conscious design. Looked at from an engineering perspective, language is a kind of disaster. [16]

Natural language clearly being not designed must lack the advantages of a well- and deliberately designed languagecomplete with its verification. But natural languages have a distinct advantage-they support discovery and thought formulation-of just the sort the artists we've looked at so far have talked about. The messiness of natural languages gives them a power that we miss when we write in artificial languages, such as programming languages.

...natural language and the messy qualities that give it so much flexibility and power, and that make it so much more than a simple communication device. The ambiguity and lack of precision allow it to serve as an instrument of thought formulation, of experimentation and discovery. We don't have to know exactly what we mean before we speak; we can figure it out as we go along. Or not. [16]

And in the hands of a careful writer, natural language can be as precise as it needs to be. Most programming language specifications have a core in natural language.

At the same time natural language still works as an instrument of thought transmission, one that can be made extremely precise and reliable when we need it to be, or left loose and sloppy when we can't spare the time or effort. [16]

Let's look at some code! <right below $>$ [17]

Beautiful. We all know a language like this one, so it should be clear what it does, no?

Now look at some other code at the top of the next page [17].

This code is almost the same as the previous, but its author did something different and additional. Art and clarity were added. ${ }^{7}$ Compilers don't care what names things have as long as they are precise and accurate in their distinctions. People are also interested in understanding, and here what can only

${ }^{7}$ You might believe that an explanation was added, but the combination of the pure code + the artistic namings is the explanation you're seeing. What was added (only the namings) by itself would be a work of art.

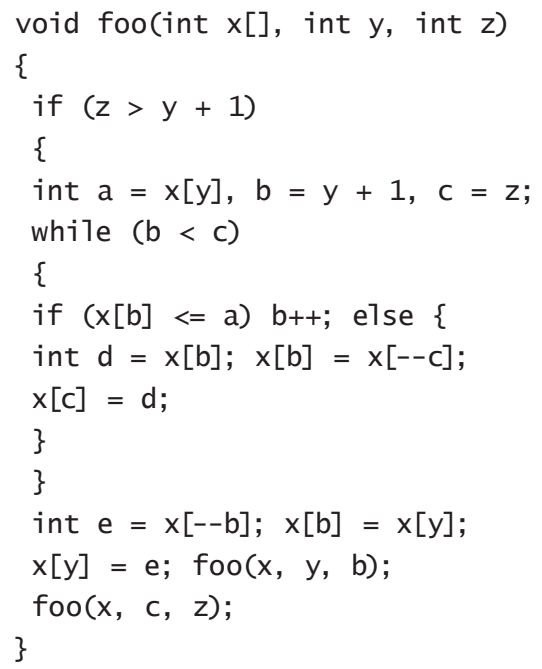


void quicksort(int array[], int begin, int end)

\{

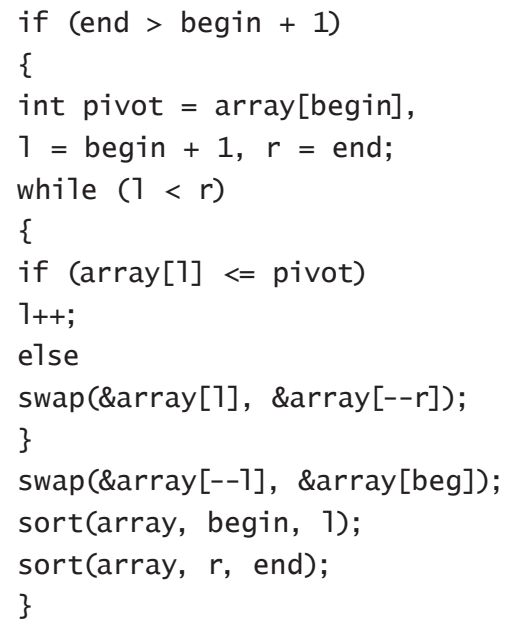

be called art has aided that aspect. Or perhaps, artistry was used to layer on an intended interpretation.

When messiness is missing, people naturally add it back by creating their own natural language on top of the parts of the artificial one that provide wiggle room. This is what's happened in the example below [17].

Art can go pretty far in this direction. There is no need to run the shell script below to get its humor. By itself it's a form of light verse, worthy of Ogden Nash, perhaps.

Earlier we talked about artistic processes. Poets and others sometimes engage in processes of defamiliarization in order to see the world differently. At the top of the left column on

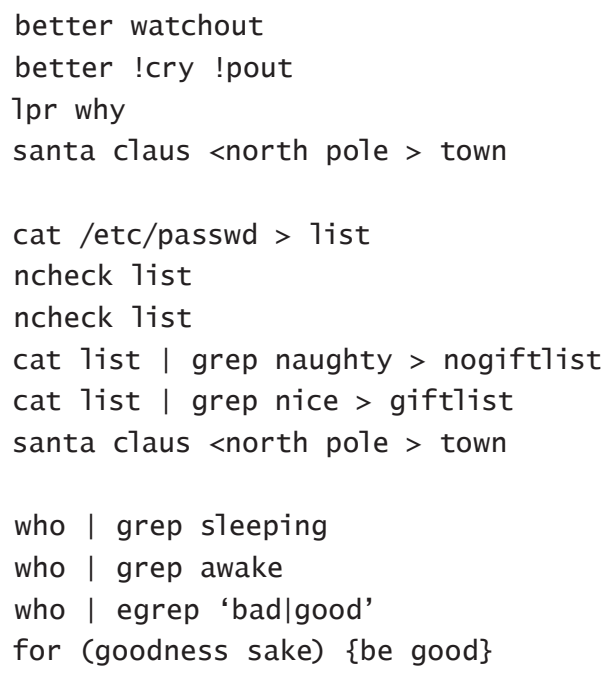

the next page is a poem rpg "wrote" by using Babelfish as a defamiliarization aid. A Robert Frost poem was run through a number of cycles of translation to and through other languages then back to English to undo the idioms and figures of speech that Frost used originally, producing a set of raw language with which to start to construct a poem-a poem both weirdly similar to the original and dementedly different . Just glance at it for a minute.

Frost's original [18] is at the top of the right column on the next page.

When we think formally about creative acts, the question arises: Where does new stuff come from? The philosopher Charles Sanders Peirce recognized that traditional logical induction and deduction were closed wrt prior assumptions and data: they cannot produce new ideas. He proposed $\boldsymbol{a} \boldsymbol{b}$ duction to explain the form of reasoning that leads to new ideas. Informally, such an inference leads from an observation of a situation that is not yet understood to a hypothesis that, if true, explains the observed phenomenon. Peirce wrote:

Now, that the matter of no new truth can come from induction or from deduction, we have seen. It can only come from abduction; and abduction is, after all, nothing but guessing. We are therefore bound to hope that, although the possible explanations of our facts may be strictly innumerable, yet our mind will be able, in some finite number of guesses, to guess the sole true explanation of them. That we are bound to assume, independently of any evidence that it is true. Animated by that hope, we are to proceed to the construction of a hypothesis. [19]

Here're brief descriptions of abduction, deduction, and induction. In deduction, one proceeds from an antecedent $a$ by logical manipulation to a consequent $b$. In induction, one proceeds from a set of structured empirical observations of $a$ and $b$ together to infer that $a \rightarrow b$. In abduction, one observes $b$-some phenomenon not yet understood-and guesses that an antecedent $a$ accounts for $b$ (i.e., $a \rightarrow b$ ), giving rise to the hypothesis, a. Now, having a hypothesis, normal hypotheticodeductive science can begin-verification.

E.g., suppose you know that all the stones on a particular Virginia beach are white. Then you see white stones on a table next to the beach. Deduction does not dictate the stones are from the beach-perhaps a truck driver from Missouri left them there. There are no regular observations of such stones having come from the beach, so induction is useless. A reasonable abductive inference, however, is that the stones are from the beach. This illustrates the idea of abduction as inference to the best explanation. With hypothesis in hand, one can then deduce consequences and test the theory. One might 


\section{Stopping by http://babelfish.altavista.com on a Snowy Evening}

Here is a task whose outcome is certain:

Thinking of someone's forest

and then thinking whether this forest is that someone's.

And as for his house (I've picked this up):

it is certainly located in town.

I am stopped here paying attention to the snow above, observing the trees filling in above the snow.

My eye finds comfort in this.

As for my horse, he strangely and narrowly stops.

I am small, me and the small end of the tree both agree.

To the horse, we are stopped between a farm and the frozen sea.

This evening is the strangest and the darkest of the year, the horse must think.

His harness bells are his only user interface.

These bells are installed to a flange by some wiring, and so

he gives the flange a shock, vibrating the wires,

thereby jolting the bells (giving them a restlessness)

in order to pose me a question:

Is there some kind of mistake here?

Surely a certain error exists.

He is a small horse.

There is only one other sound,

a different sound like a clay tone,

but only to the extent of a thin layer or a languid ribbon

forming a closed loop: the sweepback of a light breeze

over downy soft flakes-a simple, easy wind;

flakes like cotton wool or hair

or a rag for cleaning, which is the same thing.

Or maybe it sounds like this:

khlop!

(I am excited by this.)

Woods are attractive. Likable. Lovable, even.

Or sometimes-obscure. One of the trees

is dark and from a place which is deep.

And you know what they say: Dark and deep are deep.

But I am held to obligations which I must maintain.

Before I sleep I must resume my outward journey.

(And other unspecified things of the same class.)

do a statistical test of table-stone sizes against beach-stone sizes, or do a comparative analysis of chemical characteristics.

Abduction engages the imaginative capacity of the human mind to envision possible worlds ("these stones came from the beach"). It is thus a modal form of logical reasoning, and a form capable of producing a new idea: a "logical leap of the mind."

Abduction is also non-monotonic-the validity of the inference is always contingent on future information. If the chemical analysis comes back negative, well, then, the stones really weren't from the beach after all. Such a willingness to guess a good solution - to go with it-open to reconsidering it, is essential to such modern software practices as agile programming.

Before dismissing guessing as unscientific, consider Feynman's explanation of how one makes scientific discoveries:

In general, we look for a new law by the following process. First we guess it. Then we compute the con-

\section{Stopping By Woods on a Snowy Evening}

Whose woods these are I think I know.

His house is in the village though;

He will not see me stopping here

To watch his woods fill up with snow.

My little horse must think it queer To stop without a farmhouse near Between the woods and frozen lake

The darkest evening of the year.

He gives his harness bells a shake

To ask if there is some mistake.

The only other sound's the sweep

Of easy wind and downy flake.

The woods are lovely, dark and deep.

But I have promises to keep,

And miles to go before I sleep,

And miles to go before I sleep.

sequences of the guess to see what would be implied if this law that we guessed is right. [20]

Feynman worked abductively. The Stanford Encyclopedia of Philosophy states:

Scientific method begins with abduction: a conjecture or hypothesis about what actually is going on. Then, by means of deductive inference, conclusions are drawn from the hypothesis about other things that must obtain if the hypothesis is assumed to be true. These other things, it is hoped, can be experimentally tested-for. Finally, hypothesis-testing is performed by seeking experimentally to detect something that has been deduced to obtain from the hypothesis. [21]

The concept of a form of reasoning that leads to conclusions that are not necessary but possible is in fact very old. Aliseda-Llera notes that it dates to Aristotle's apogoge [22]. Laplace addressed in detail the process of reasoning from effects (data) to causes (hypotheses). Peirce was responsible for the name, abduction, and for placing abduction in the context of what then emerged as modern logic.

Nor is the idea new that abductive reasoning is important to invention and discovery. Peirce was clear on the matter. And later in the late 1950s, the philosopher of science, Norwood Russell Hanson, argued against the notions of Popper and others who insisted on hypothetico-deductive (H-D) processes as the essential heart of the scientific method. Hanson was interested in the intellectual activity that gave rise to novel hypotheses, and not so much in the subsequent (and in his view more mundane and formal) activities of deducing consequences and testing them. He referred back to the Peircian notion of abductive reasoning, arguing that it instead was essential to creativity in science: 
Physicists do not start from hypotheses; they start from data. By the time a law has been fixed into an $H-D$ [hypothetico-deductive] system, really original thinking is over. [23]

Hanson's position led to arguments in the philosophy of science over several decades. For example, an infinite number of hypotheses can be inferred abductively from a single observation; how does one choose? Sami Paavola presented a summary of the principal objections and a refutation:

Deductive logic is not enough, and the model of abductive inference is especially needed in order to understand the processes of discovery. But abduction in itself is not enough. Besides validity considerations (which are in themselves important in abduction) there is the art of using (abductive) reasoning. [24]

Abduction provides power when used intelligently, strategically, artfully, in a value-seeking process. Getting a little closer to home, we view critical parts of the software system design process as involving not the deduction of code from specifications, but creative exploration and discovery.

One of the keys to an artful and effective use of abduction is iteration-iterated guessing, testing, and refinement of provisional hypothesis. Toshio Itoh wrote:

Abduction is both essential to and effective for creativity. Abduction, which allows a role for the personality, is the only thought process that actually fosters creativity. Abduction is outward-looking.... Abduction is self-correcting. Abduction validates or invalidates hypotheses by constantly exposing their consequences or the assumptions behind them to new facts and continually subjecting everything to practical verification. [25]

Iterative development processes work not by hoping to derive everything from a specification assumed to be correct, but by continual guessing, testing, and refining. Development involves design. In The Design of Business: Why Design Thinking is the Next Competitive Advantage, Roger Martin states:

Whether they realize it or not, designers live in Peirce's world of abduction; they actively look for new data points, challenge accepted explanations, and infer possible new worlds. [26]

Martin argues that most contemporary organizations not only fail to support this style of thinking: they actively stamp it out. The problem is that the needs of creative design, which seeks valid constructs-constructs that actually solve the right problems-conflict with demands for reliable performance which is obtained by processes that eschew the unpredictability of creativity: e.g., delivering predictable profits on a quarterly basis through measurement and inductive projection. Martin says, "delving into mysteries is the most expensive activity...because you literally don't know what you are doing..." Long-term viability of economic enterprises, Martin argues, is in balancing reliability and validity.

Martin formulates his proposal for business in terms of three stages of knowledge refinement. One starts with a mystery, a problem, an anomaly, that "excites our curiosity but eludes our understanding." The leap to the next stage is by abduction: in the form of a guess (sometimes wild) as to an appropriate solution. The guess, or hypothesis, is a "concept providing for a simplified and manageable understanding [of what is often a very complex domain] and the ability to focus efforts, to guide organized exploration of possibilities." Such a hypothesis leads to a valid heuristic solution. The third step is to systematize that heuristic solution: to make an algorithm, a certified production process, which guarantees that results with particular attributes will be produced reliably.

Martin's central argument is that contemporary organizations are overly focused on reliability rather than on validity: for example, on producing hamburgers with vanishingly small parameter variations, rather than on producing what people really want to eat. Mihnea Moldoveanu, quoted in Martin's book, argues, "the 'inductive fallacy' is that of inferring validity from reliability."

It's easy to see that some artists know a lot about abduction, at least tacitly. The sentences in a short story are not sufficient to deduce the story that appears in your head as you read it. Good short story writers know how much is needed for most readers to abduce essentially the same story.

And producing the work of art in the first place requires constant discovery and guessing-because all works of art are works of exploration and discovery. Robert Boswell, the fiction writer, puts it like this:

I have grown to understand narrative as a form of contemplation, a complex and seemingly incongruous way of thinking. I come to know my stories by writing my way into them. I focus on the characters without trying to attach significance to their actions. I do not look for symbols. For as long as I can, I remain purposefully blind to the machinery of the story and only partially cognizant of the world my story creates. I work from a kind of half-knowledge.

In the drafts that follow, I listen to what has made it to the page. Invariably, things have arrived that I did not invite, and they are often the most interesting things in the story. By refusing to fully know the world, I hope to discover unusual formations in the landscape, and strange desires in the characters. By declining to analyze the story, I hope to keep it open to surprise. Each new draft revises the world but does not explain or define it. I work through many drafts, 
progressively abandoning the familiar. What I can see is always dwarfed by what I cannot know. What the characters come to understand never surpasses that which they cannot grasp. The world remains half-known.

There can be no discovery in a world where everything is known. A crucial part of the writing endeavor is to practice remaining in the dark. [27]

In the cycle of explore-discover-understand, creative acts take place in the discover phase, where abduction-guessing-happens. Exploring with an open mind-perhaps with defocused attention - an artist or scientist might guess / hyothesize that something might be the case or might be worth turning into a work of art. Then in understanding the guesseither verifying / validating it as a scientist or working out its best artistic expression as an artist, one can then embark on further exploration, further discovery, and further understanding.

The astronomer Heber Curtis had a hunch (a guess constituting a possible discovery) that the entire universe was not the same as the Milky Way (our galaxy), and that the Andromeda Nebula was actually a separate galaxy. This was the subject of the Great Debate in 1920 between Heber Curtis and Harlow Shapley. Later, Edwin Hubble believed if he could find (explore; discover) a Cepheid variable star in the Nebula, information about its luminosity and period would tell us how far away it was and settle (understand; verify) whether it was in the Milky Way. And in fact Andromeda turned out to be a separate, far away galaxy. This is an example of fractal nature of the explore-discover-understand process. And also that the process need not occur within one scientist's mind.

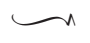

But not all scientists-or even artists-work exclusively in the realm of "stuff"; not all writers write without a plan, a concept; not all scientists work exclusively from data to hypothesis. There is another relevant dimension which addresses this objection: the dimension of experimental to conceptual.

Artists who have produced experimental innovations have been motivated by aesthetic criteria: they have aimed at presenting visual perceptions. Their goals are imprecise, so their procedure is tentative and incremental. The imprecision of their goals means that these artists rarely feel they have succeeded, and their careers are consequently often dominated by the pursuit of a single objective. [27]

When we first started thinking about art, we believed that all art-especially writing-was what is called experimental art. We believed that a good writer just started out in some direction-even if he or she planned out the piece in great detail-but sooner or later the piece would take over and the writer would be along for the ride.

But this isn't true. The poems we just showed you, and to an extent the code as well, are not the product of unbounded exploration and discovery. Each of them was based on a concept.

In contrast, artists who have made conceptual innovations have been motivated by the desire to communicate specific ideas or emotions. Their goals for a particular work can usually be stated precisely, before its production, either as a desired image or a desired process for the work's execution. Conceptual artists consequently make detailed preparatory sketches of plans for their paintings. [28]

In the defamiliarized Frost poem, rpg's concept was to use Babelfish to make a set of ridiculous translations of the wellknown poem in order to free it of its now-familiar wording. He had it translate the poem from English to Greek, then to Korean, then to Japanese, then to German, and back to English; he used a set of such cyclic translations as the starting point for his poem. This is conceptual art.

For experimental artists:

... planning a painting is unimportant. The subject selected might be simply a convenient object of study, and frequently the artist returns to work on a motif he has used in the past. Some experimental painters begin without a specific subject in mind, preferring instead to let the subject emerge as they work. Experimental painters rarely make elaborate preparatory sketches. Their most important decisions are made during the working stage. The artist typically alternates between applying paint and examining the emerging image; at each point, how he develops the image depends on his reaction to what he sees. [28]

For conceptual artists:

...planning is the most important stage. Before he begins working, the conceptual artist wants to have a clear vision either of the completed work or of the process that will produce it. Conceptual artists consequently often make detailed preparatory sketches or other plans for a painting. With the difficult decisions already made in the planning stage, working and stopping are straightforward. The artist executes the plan and stops when he has completed it.

...extreme practitioners...make all the decisions for a work before beginning it. It is unclear, however, if this is literally possible. There are artists who came close to it, and perhaps achieved it, during the 1960s, 
by making plans for their work and having these plans executed by others. [28]

In painting, Cézanne is an experimental artist and Picasso is conceptual. Generally and interestingly, the masterpieces of experimental artists are done at an older age than for conceptual artists.

Back in the 1970s, a curmudgeonly professor at the MIT AI Lab noticed the experimental-conceptual dimension. Joseph Weizenbaum is best known for writing the Eliza program, which pretended-in a trivial fashion - to be a Freudian therapist.

But he was irked by the programmers at the AI Lab, especially Richard Stallman. He painted a picture of the "ordinary professional programmer" and contrasted it with the "hacker," meaning someone like Stallman.

The professional programmer worked like a conceptual artist, making plans in detail, and perhaps not even executing them himself, but delegating that to an underling-or perhaps an apprentice.

The ordinary [professional] programmer will...generally do lengthy preparatory work, such as writing and flow diagramming, before beginning work with the computer itself. His sessions with the computer may be comparatively short. He may even let others do the actual console work. He develops his program slowly and systematically. When something doesn't work, he may spend considerable time away from the computer framing careful hypotheses to account for the malfunction and designing crucial experiments to test them.... When he has finally composed the program he set out to produce, he is able to complete a sensible description of it and turn his attention to other things. [29]

The hacker-whom he delicately called a "compulsive programmer"-acts like an experimental artist, just digging in with only the dimmest glimmer of what to do, and eventually something comes out.

The compulsive programmer is usually a superb technician,...one who knows every detail of the computer he works on, its peripheral equipment, the computer's operating system, etc....He can write small subsystem programs quickly, that is, in one or two sessions of, say, 20 hours each.... His main interest...is in very large, very ambitious systems of programs.... [T] he systems he undertakes to build have very grandiose but extremely imprecisely stated goals. Some examples...are: new computer languages to facilitate man-machine communication; a general system that can be taught to play any board game; a system to

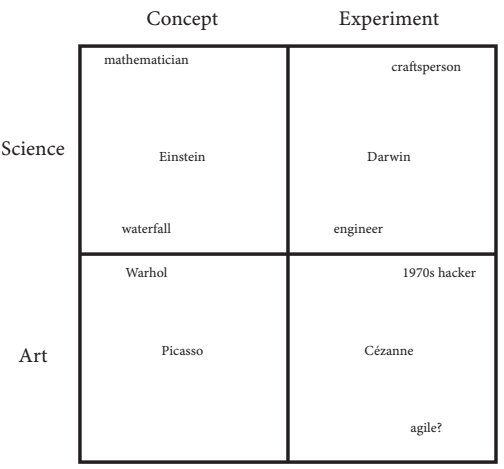

make it easier for computer experts to write supersystems. [29]

And like the experimental artist or poet, if anything good emerges it's because of technique and skill, not knowledge. Not something to form theories about, not something amenable to science.

The compulsive programmer...calls what he does "hacking."... He cannot set before himself a clearly defined long-term goal and a plan for achieving it, for he has only technique, not knowledge. He has nothing he can analyze or synthesize; in short, he has nothing to form theories about....

(It has to be said that not all hackers are pathologically compulsive programmers. Indeed, were it not for the often, in its own terms, highly creative labor of people who proudly claim the title "hacker," few of today's sophisticated computer time-sharing systems, computer language translators, computer graphics systems, etc., would exist.) [29]

The space of how people work at creative endeavors is at least as complex as depicted in the diagram above.

Let's start with conceptual artists. Sometimes they are forced into it because their medium is not malleable, not like words on a page or in a file. (Note that the advent of computers for writing made it easier to be an experimental writer for having a much more malleable medium for the words to live on or in.)

Experimental artists are like Cézanne, like a lot of precomputer-age poets, like the fiction writer Robert Boswell, like hackers in the 1970s perhaps.

Conceptual scientists are like mathematicians and Einstein; like theoretical physicist such as Feynman.

Experimental scientists are like engineers, or the complexity scientists who use agent-based simulations to understand systems and try to manipulate them.

Conceptual creatives embrace abstractions-symbol systems or sketches that show only the big ideas; experimental 


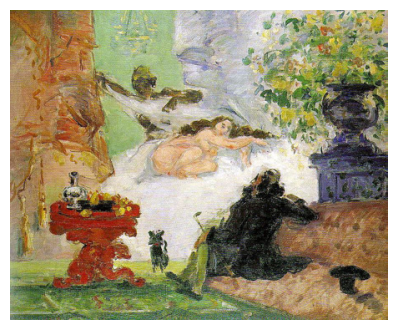

Paul Cézanne: A Modern Olympia

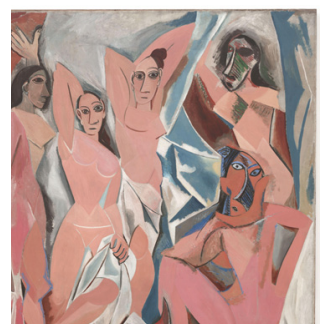

Pablo Picasso: Les Demoiselles d'Avignon ones like to get their hands or minds around the stuff itself. Kent Beck calls source code "stuff." Drew McDermott, a computer scientist at Yale, once said, "what I like about Lisp is that you can feel the bits between your toes."

Artists believe that the key part of making art is exploration and discovery, while scientists believe the key part of doing science is understanding and verification. Notice that we wrote "believe."

In fact, generally, artists evaluate their discoveries and revise like crazy-writers convene circles of friends and workshops to examine and critique drafts. And in fact, scientists have nothing to understand and verify unless they have explored and discovered. Conceptual artists and scientists play with and explore abstractions and ideas-their "stuff."

Scientists and artists are blind to what they actually do and how they really work. The problem with the diagram on the previous page is that it is static-everyone working on a creative project moves all over this 2-dimensional space while working. - Because they are all people, and people mostly work the same ways. Sometimes they explore and discover, sometimes they verify and control, sometimes they work in the realm of ideas, and sometimes they manipulate materials.

Cézanne played. He struggled to develop an authentic observation of the seen world by the most accurate method of representing it in paint that he could find. To this end, he structurally ordered whatever he perceived into simple forms and color planes (abstractions). His artistic goals were things he could only approach and never achieve, and that's why he kept trying, with his best works coming late in life. His ideas were not concepts that came in a flash, but something he painted and painted and painted. He stalked art, he pursued it like a series pursues its convergence.

Picasso thought of himself as someone from whom art sprung whole. Les Demoiselles d'Avignon is considered by many to be his masterpiece. He carefully planned it. The painting portrays five nude prostitutes in a brothel in Barcelona. The figures are physically jarring, none conventionally feminine, all slightly menacing, and each is rendered with an angular and disjointed body shape. Two of the women have African-mask-like faces, giving them a savage and mysterious aura. This is a variant of Primitivism. Picasso also abandoned perspective in favor of a flat, two-dimensional picture plane.
Picasso stated that his art was the result of what he had found-as opposed to showing his seeking, as Cézanne didbut he claimed to not believe in research.

I can hardly understand the importance given to the word "research" in connection with modern painting. To find, is the thing....

When I paint my object is to show what I have found, not what I am looking for....

I have never made trials or experiments. Whenever I had something to say, I have said it in the manner in which I have felt it ought to be said. [30]

Yet, for Les Demoiselles d'Avignon, Picasso did over 400 studies and sketches, a record for artistic preparation. If this isn't playing, experimenting, and researching, we confess to not knowing what those things are.

Artists, scientists, and engineers approach their work in similar ways, with nearly the same set of creative and conceptual tools. This seems obvious to us, but maybe not to most, and possibly not to scientists. What if it were possible to be a better scientist by using techniques from art?

Consider this experiment: Look at the grammar at the bottom of the column. A scientist is shown 45 strings of length between 6 and 9 generated by it, and asked to copy down each one. The original list and copies are removed, and a short time later, the scientist is asked to look at 60 strings made up of the letters $\mathrm{X}, \mathrm{V}, \mathrm{M}, \mathrm{R}, \mathrm{\&} \mathrm{T}, 30$ of which were generated by that grammar and 30 by a different one; next, the scientist is told that the strings he or she had copied had something in common, and he or she is asked to classify these 60 strings according to whether it had that same thing in common.

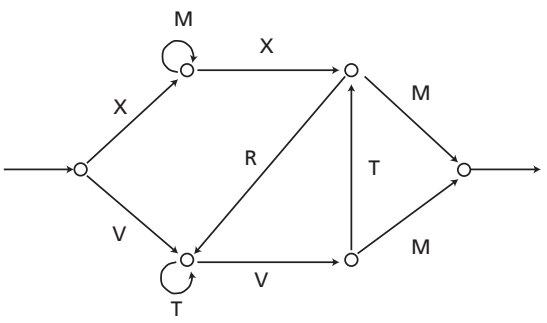


The classification task is a mystery, and coming up with a grammar that corresponds to the original 45 strings requires guessing-abduction. But, any performed abduction takes place implicitly in the scientist's mind. What's been described is a common tool to measure implicit learning-or implicit abduction: what grammar can give rise to the 45 test strings?

Now suppose a group of 40 people, broken into two 20 -person groups, is asked to do the above experiment, but before that, each group is asked to read an illustrated short story. One group is asked to read a revision of Kafka's "The Country Doctor," which is a (slightly) absurdist story [31]. The other group is asked to read a straightforward version of the same story [31]. What would happen?

Camus wrote about Kafka:

In this fundamental ambiguity lies Kafka's secret. These perpetual oscillations between the natural and the extraordinary, the individual and the universal, the tragic and the everyday, the absurd and the logical, are found throughout his work and give it both its resonance and its meaning. [32]

Travis Proulx and Steven J. Heine did this experiment, and found that the group that read the absurd version of the story were $26 \%$ more accurate (correctly identified strings from the grammar) than the other, and classified 33\% more strings as belonging to the grammar (ignoring whether they were right or wrong) [33]. Proulx and Heine claim this latter result is because of increased motivation, but perhaps it's just increased energy.

The straightforward version of the story is linear and boring. It doesn't require any guesswork to get its "meaning," which in this case is nothing more than its (dull) plot and happy ending. The absurd version is not particularly crazy or surreal, but it does call for abduction to try to make sense of it. Like many surreal and absurdist stories, no abductions work well, and the reader is left with a sense of mystery and strangeness. But the brain is hard at work abducing and becoming defamiliarized, just as we saw other artists doing. No wonder, then, that with the mind open to far-flung connections it is able to learn a little more effectively and confidently.

Over the past century or so, there have been persistent and dedicated efforts to "scientifically" control development and production processes. Such efforts have made a big difference to the quality of manufacturing though we can't say it's helped the quality of design much.

Scientific processes have also been pushed in the realm of software development, and we believe this is a significant error-an error based on misperceiving how work actually takes place in designing and creating software.

Scientific processes, whether for product development, manufacturing, or service delivery, seek to minimize vari- ances in task execution through the imposition of tight constraints, measurement systems, and feedback control.

An artistic process tolerates or even welcomes a variety of inputs and works to produce the best (or at least an acceptable) result given the inputs and the situations encountered while executing the process. In particular, an artistic process can adapt to very poorly stated requirements or even no requirements at all (aside from the production of something of value). Artistic processes endeavor to invent and blaze new trails. In many cases the value of the outcome of an artistic process will be determined only after the product has been produced, though it's often possible to make some judgments along the way. [34]

Many aspects of software development require an artistic approach, an approach that acknowledges that sometimes exploration and discovery are required. Sometimes artistic processes are experimental-because source code and software are malleable and subject to "play"-but sometimes they are conceptual, achieved through blackboard designs, role playing, simulations, and modeling. Moving through the art / science / concept / experiment space is fractal.

Artistic approaches work best when requirements are sparse, incomplete, or even simply wrong or poorly stated. They also work where invention is desired.

Yet, pressure continues to be placed on software creation to fall in line with scientific processes. This is because, we believe, people would really like to see software creation conform to their caricature of an engineering discipline. Software creation is not there yet. The manufacturing metaphor came to be when producing code a line at a time looked a lot like laborers laying sleepers and rails.

But even producing software where everything is well understood, mistakes are made and programmers spend their time trying to wrangle the code into behaving the way they clearly see it in their minds.

Always, the creation of software requires at least one cycle through the explore-discover-understand space-if for no other reason than vision, requirements, and specifications are a mystery, while design and code are abductions. When we bother to watch how work gets done-regardless of the theory that sits in your head about how it should be donewe see this everywhere in software development.

And this isn't only a local phenomenon-it happens at all levels. This is what Weizenbaum missed when he watched ordinary professional programmers-even though they didn't sully their hands with actually punching in code and overseeing its execution, they were forced to reconsider, replan, and reformulate, just as Picasso did in his sketchbooks: they played with "stuff" that happened to be abstract.

The real problem with the scientific approach to software isn't that it's wrong all the time; it's just that it's not right all the time. It's a one-size fits all philosophy. People who dig into the nature of software creation recognize that in many cases there is a cycle of exploration and discovery with a heavy 
dose of getting it to work. This is in part because when we develop software we are creating novel worlds without imposed constraints on what's possible-there are only the constraints we imagine up to put in place. Circumstances dictate the appropriate process. Perhaps now we can begin to distinguish conditions when it is likely to pay to go abductive / creative / artistic rather than deductive / scientific.

We need to look closely at what creative work is really like and adopt techniques and processes that support it. Education is part of it. Possibly artistry has been pushed aside because it's not well understood. A common definition of an artist is "a person who expresses himself through a medium." Certainly some artists do this, but not all, and perhaps not the majority. It would be just as true to say that an engineer is "a person who expresses himself through bridges."

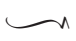

Explore: wander / defamiliarize

Discover: guess / abduce

Understand: validate / ask—-did you build the right thing?

\section{References}

[1] Knott, Bill. Nights of Naomi. Barn Dream Press. Boston. 1971.

[2] Wikipedia. "Superstring Theory."

[3] yesyesnono photostream. Flickr.com. 2010.

[4] Jackson Pollock.

[5] Sanda Illescu.

[6] Kevin J. Sullivan. Personal communication.

[7] Kuhn, Thomas. The Structure of Scientific Revolutions. University Of Chicago Press. 1996.

[8] Wikipedia. "Positivism."

[9] Lakatos, Imre; Feyerabend, Paul. For and Against Method. Edited by Matteo Motterlini. University of Chicago Press, Chicago \& London. 1999.

[10] Latour, Bruno. Science in Action: How to Follow Scientists and Engineers through Society. Harvard University Press. Cambridge, MA. 1988.

[11] Crawford, Matthew, B. Shop Class as Soulcraft: An Inquiry Into the Value of Work. Penguin. New York. 2009.

[12] Langley, Pat; Simon, Herbert A.; Bradshaw, Gary L; Zytkow, Jan M. Scientific Discovery: Computational Explorations of the Creative Processes. The MIT Press. Cambridge, MA. 1987.

[13] Turchi, Peter. Maps of the Imagination: The Writer as Cartographer. Trinity University Press. 2004.

[14] Stafford, William. Writing the Australian Crawl. University of Michigan Press. Ann Arbor. 1987.

[15] Hass, Robert. Personal communication. Squaw Valley, CA. 2008.

[16] Okrent, Arika. In the Land of Invented Languages: Esperanto Rock Stars, Klingon Poets, Loglan Lovers, and the Mad Dreamers Who Tried to Build A Perfect Language. Spiegel \& Grau. New York. 2009.

[17] Baniassad, Elisa; Myers, Clayton. "An Exploration of Program as Language." Proceedings of the $24^{\text {th }}$ ACM SIGPLAN Conference on Object-Oriented Programming, Systems, Languages, and Applications. Orlando. 2009.

[18] Frost, Robert. New Hampshire. Henry Holt. New York. 1923.

[19] Hartshorne, Charles; Weiss, Paul. Collected Papers of Charles Sanders Peirce, Volumes I and II: Principles of Philosophy and Elements of Logic. Harvard University Press. Cambridge, MA. 1958.

[20] Feynman, Richard. A Life in Science. Dutton. New York. 1997.

[21] Burch, Robert. “Charles Sanders Peirce.” Zalta, Edward-N. ed. The Stanford Encyclopedia of Philosophy. Stanford University. Winter 2008 edition. 2008.

[22] Aliseda-Llera, Atocha. Seeking Explanations: Abduction in Logic, Philosophy of Science, and Artificial Intelligence. Stanford University Ph.D. Dissertation, Department of Philosophy. 1997.

[23] Hanson, N. R. Patterns of Scientific Discovery. Cambridge University Press. New York. 1961.

[24] Paavola, Sami. "Abduction as a logic and methodology of discovery: The importance of strategies." Foundations of Science, 9(3):267-283. 2004.

[25] Itoh, Toshio. A New Approach to Future Enterprises: Abduction for Creativity. Ohmsha, Ltd. Tokyo. 1996.

[26] Martin, Roger. The Design of Business: Why Design is the Next Competitive Advantage. Harvard Business Press. Boston, MA. 2009.

[27] Boswell, R., The Half-Known World: On Writing Fiction. Graywolf Press. St. Paul, MN. 2008.

[28] Galenson, David W. Old Masters and Young Geniuses: The Two Lifecycles of Artistic Creativity. Princeton University Press. Princeton, NJ. 2007.

[29] Weizenbaum, Joseph. Computer Power and Human Reason. Penguin. New York. 1984.

[30] Picasso, Pablo. 1923 interview.

[31] http://dreamsongs.com/Files/ImplicitLearningStories.pdf. From Proulx \& Heine [33].

[32] Camus, Albert. "An Absurd Reasoning." The Myth of Sisyphus and other essays. J. O'Brien editor and translator. Vintage Books. New York. 1955.

[33] Proulx, Travis; Heine, Steven J. “Connections From Kafka: Exposure to Meaning Threats Improves Implicit Learning of an Artificial Grammar.” Psychological Science. Vol. 20, No. 9. 2009.

[34] Hall, Joseph M.; Johnson, M. Eric. "When Should a Process Be Art, Not Science?” Harvard Business Review. Cambridge, MA. March 2009. 